\title{
Social rhythm and other chronobiological findings in juvenile myoclonic epilepsy
}

\author{
R.L. Schimitt ${ }^{\mathrm{a}, \mathrm{b} *}$, J.A. Bragatti ${ }^{\mathrm{b}, \mathrm{c}}$, R. Levandovsky ${ }^{\mathrm{a}, \mathrm{d}}$, M.P. Hidalgo ${ }^{\mathrm{a}, \mathrm{b}, \mathrm{d}, \mathrm{e}}$ and \\ M.M. Bianchin ${ }^{\text {b,c }}$
}

${ }^{a}$ Laboratório de Cronobiologia, Universidade Federal do Rio Grande do Sul, Porto Alegre, Brazil; ${ }^{b}$ Programa de pós-graduação em Medicina: Ciências Médicas, Universidade Federal do Rio Grande do Sul, Porto Alegre, Brazil, ${ }^{c}$ Division of Neurology, Universidade Federal do Rio Grande do Sul, Porto Alegre, Brazil, ${ }^{d}$ Programa de pós-graduação em Ciências Médicas:

Psiquiatria, Universidade Federal do Rio Grande do Sul, Porto Alegre, Brazil; ${ }^{e}$ Departamento de Psiquiatria e Medicina Legal, Faculdade de Medicina, Universidade Federal do Rio Grande do Sul, Porto Alegre, Brazil

(Received 26 December 2014; accepted 30 January 2015)

\begin{abstract}
We evaluated the correlation between chronobiological variables and characteristics of juvenile myoclonic epilepsy. Sample: 17 individuals epileptic outpatients and respective controls. Instruments: The Social Rhythm Metric for social zeitgebers, lux meter, and an $\mathrm{ACT} 10^{\circledR}$ thermistor for activity-rest rhythm, light exposure, and peripheral body temperature. Regularity scores showed an inverse correlation with age at disease onset $(r=-0.5 ; p<0.05)$, but not with disease duration or stabilization time. A significant intergroup difference was recorded for mean diurnal peripheral temperature $(p<0.01)$ and activity amplitude $(=0.06)$. There was a correlation between activity and temperature means in both groups. These results underscore the relationship between epilepsy and the biological clock on a physiological level. Epilepsy, in turn, is influenced by the circadian rhythm, indicating the potential involvement of the body's internal clock in the development of the disease or the seizure recurrence pattern.
\end{abstract}

Keywords: social rhythm; epilepsy; chronobiology

\section{Introduction}

Evidence suggests interaction between epilepsy and the sleep-wake cycle (Herman et al. 2001). Epilepsy influences circadian rhythms, the hormonal profile, and body temperature (Laakso et al. 1993; Bazil et al. 2000; Hofstra \& deWeerd 2009). Epilepsy, in turn, is influenced by the circadian rhythm, indicating the potential involvement of the body's internal clock in the development of the disease or the seizure recurrence pattern (Hofstra et al. 2009). Light is an exogenous synchronizer of human biological rhythms and some forms of epilepsy are highly photosensitive (Parain \& Blondeau 2000; Yang et al. 2008). Moreover, it is known that sleep deprivation can precipitate seizures (Robinson et al. 2008) and although some medication used to treat the disease can cause sleep abnormalities, most act through a mechanism that stabilizes sleep patterns (Almeida et al. 2003).

\footnotetext{
*Corresponding author. Email: reginalopesschimitt@gmail.com
} 
Juvenile myoclonic epilepsy (JME) is an idiopathic generalized epileptic syndrome with specific circadian alterations, primarily in the sleep cycle. Patients with JME tend to exhibit a delayed phase sleep cycle, prolonged sleepiness, and functional impairment in the first part of the day (Punz \& Schmitz 2006). These abnormalities have yet to be fully elucidated, but it is suggested that patients with JME tend to lack circadian rhythmicity in their lifestyle and that lifestyle impacts symptoms (Almeida et al. 2003; Robinson et al. 2008; Yang et al. 2008). This is a plausible hypothesis, since lack of circadian rhythmicity affects sleep patterns and sleep deprivation is the primary trigger of seizures in JME (Ryasi et al. 2008).

This study was designed to investigate the interaction between JME and circadian rhythmicity. We evaluated the correlation between chronobiological variables, defined by social rhythm, activity-rest rhythm, and peripheral temperature rhythm, and variables related to chronic disease, defined by age at onset, disease duration, and symptom stabilization time, considering the demographic aspects of the sample. We believe that our findings will help elucidate how circadian rhythmicity can affect epilepsy, particularly JME.

\section{Material and methods}

We recruited 17 individuals diagnosed with JME at the neurology outpatient clinic of the Hospital de Clínicas de Porto Alegre (HCPA) and respective controls.

Participants completed a questionnaire on demographic information. Chronotypes were assessed using the Morningness-Eveningness Questionnaire (MEQ), containing 19 questions scored from 16 to 86 points, with higher scores indicating morning-type individuals and low scores identifying evening-type individuals (Horne \& Ostberg 1976).

Depressive symptoms were evaluated by the Beck Depression Inventory, consisting of 21 questions ranging from 0 to 63 points, with a cutoff score of 16 (moderate depression) (Gorestein \& Andrade 2000).

Zeitgeber is a German word coined by Jurgen Aschoff in the 1970s which loosely translates as "synchronizer" and is used to designate exogenous factors (light, exercises, food, social cues) that can synchronize biological rhythms (Schimitt, Zanetti, et al. 2010). In our study, social zeitgebers were assessed using the Social Rhythm Metric, which scores the regularity of daily life from 0 to 7 over a period of 7 days by simply counting activities during this period (Schimitt, Zanetti, et al. 2010). The activity-rest rhythm and degree of exposure to the photic zeitgeber were analyzed using an ACT10 ${ }^{\circledR}$ actigraph with a built-in thermistor and lux meter.

The study was approved by the Research and Ethics Committee of the HCPA of the Rio Grande do Sul School of Medicine and was conducted according to the principles expressed in the Declaration of Helsinki. All the study participants gave written informed consent.

\subsection{Data treatment}

Scores on the social rhythm metric were calculated using a specific algorithm (Schimitt, Zanetti, et al. 2010). Actigraph data were read with actimeter software and interpreted using El Temps ${ }^{\circledR}$ (Noguera) software to calculate the variables of temperature, light exposure, and rhythmic activity parameters, namely amplitude, mesor, and acrophase.

Statistical analyses were performed using SPSS $^{\circledR}$ software (Rowland et al. 1991). The Mann-Whitney $U$-test was applied to assess intergroup differences, the Pearson 
correlation coefficient for linear parametric analysis, and Spearman's Rho for nonparametric analysis. Results were considered significant for $p<0.05$.

\section{Results}

Demographic results are shown in Table 1. Controls showed a higher average schooling level. Patients with epilepsy exhibited a statistical trend toward higher mean depression scores than controls (Table 1).

A significant intergroup difference was recorded for mean diurnal peripheral temperature $(p<0.01)$ and activity amplitude $(=0.06)$, with controls exhibiting higher means (see Figure 1).

There was a correlation between activity and temperature means in both groups, although these were significantly higher in the epilepsy patients. While controls showed a diurnal correlation of 0.15 between mean activity and temperature, correlation was 0.65 for the epilepsy group. With respect to nocturnal correlation between mean activity and temperature, a correlation of 0.65 was recorded for controls and 0.97 for epilepsy patients (Figure 2).

Regularity scores showed an inverse correlation with age at disease onset $(r=-0.5$; $p<0.05$ ), but not with disease duration or symptom stabilization time. There was no correlation between the activity index and any of the variables related to chronic disease.

Acrophase is the time interval in which the maximum values of a variable are most likely to occur (Schimitt, Hidalgo, et al. 2010). Rayleigh's method was applied to determine the acrophase and found no differences between the groups (Figure 3).

Table 1. Demographic and chronobiological variables.

\begin{tabular}{lccccc}
\hline Variables & $\begin{array}{c}\text { Control } \\
\text { group }\end{array}$ & $\begin{array}{c}\text { Patient } \\
\text { group }\end{array}$ & $\begin{array}{c}U \text { (Mann-Whitney } \\
U \text {-test) }\end{array}$ & $\begin{array}{c}\text { W (Wilcoxon } \\
\text { test) }\end{array}$ & $p$ \\
\hline Sex & $\mathrm{M}=5 /$ & $\mathrm{M}=7 /$ & 89.5 & 155.5 & 1 \\
& $\mathrm{~F}=6$ & $\mathrm{~F}=10$ & & & \\
Age & $32 \pm 15$ & $33 \pm 13$ & 76.5 & 142.5 & 0.4 \\
BMI & $22 \pm 2$ & $25 \pm 5$ & 59 & 125 & 0.1 \\
Beck & $4 \pm 3$ & $10 \pm 9$ & 54 & 120 & 0.06 \\
Schooling & $15 \pm 3$ & $11 \pm 3$ & 23 & 176 & $<0.001$ \\
MEQ & $47 \pm 13$ & $49 \pm 9$ & 65.5 & 131.5 & 0.2 \\
SRM & $2 \pm 1$ & $2 \pm 1$ & 83 & 149 & 0.6 \\
ALI & $85 \pm 8$ & $79 \pm 11$ & 62 & 215 & 0.1 \\
Mesor temperature & $30 \pm 1$ & $28 \pm 3$ & 49 & 202 & $<0.05$ \\
Amplitude peripheral & $2 \pm 1$ & $3 \pm 2$ & 64 & 130 & 0.2 \\
$\quad$ temperature & & & & & \\
Acrophase peripheral & $326 \pm 213$ & $335 \pm 311$ & 85 & 238 & 0.7 \\
$\quad$ temperature & & & & & \\
Mesor light exposure & $176 \pm 141$ & $5 \pm 2$ & 92 & 245 & 0.9 \\
Amplitude light exposure & $272 \pm 233$ & $285 \pm 327$ & 91 & 157 & 0.9 \\
Acrophase light exposure & $769 \pm 55$ & $780 \pm 39$ & 81 & 242 & 0.5 \\
Mesor activity & $107 \pm 64$ & $83 \pm 10$ & 89 & 120 & 0.06 \\
Amplitude activity & $60 \pm 52$ & $54 \pm 10$ & 54 & 235 & 0.6 \\
Acrophase activity & $939 \pm 84$ & $925 \pm 69$ & 82 & & \\
\hline
\end{tabular}


(a)

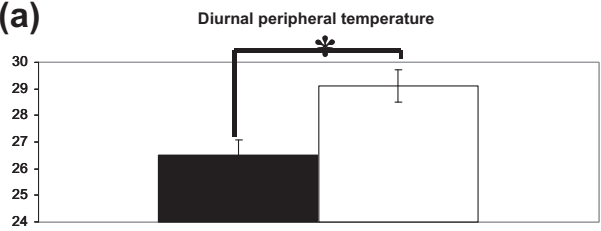

- Epilepsy group $\square$ Control group

${ }^{*} \mathrm{p}<0.01$

(c)

Diurnal Activity

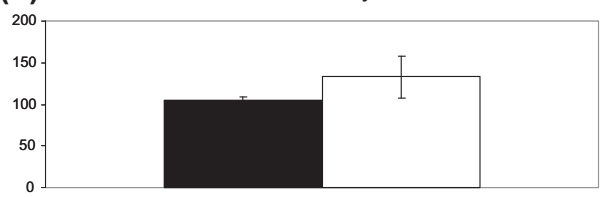

- Epilepsy Group $\quad \square$ Control Group (b) Noturnal Peripheral Temperature

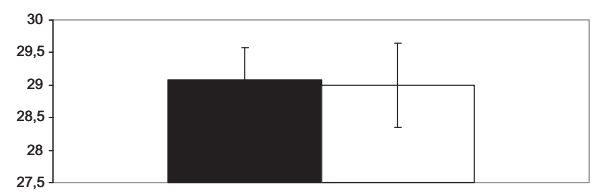

- Epilepsy Group $\square$ Control Group

(d) Noturnal Activity

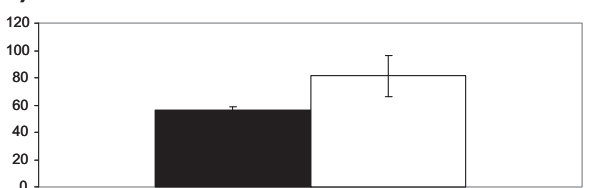

Epilepsy Group a Control Group

Figure 1. Differences among means by groups: (a) diurnal peripheral temperature; (b) noturnal peripheral temperature; (c) diurnal activity; and (d) nocturnal activity.

JME Group

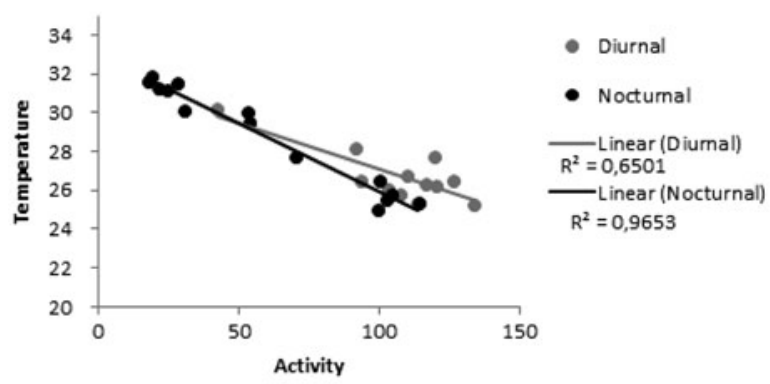

Control Group

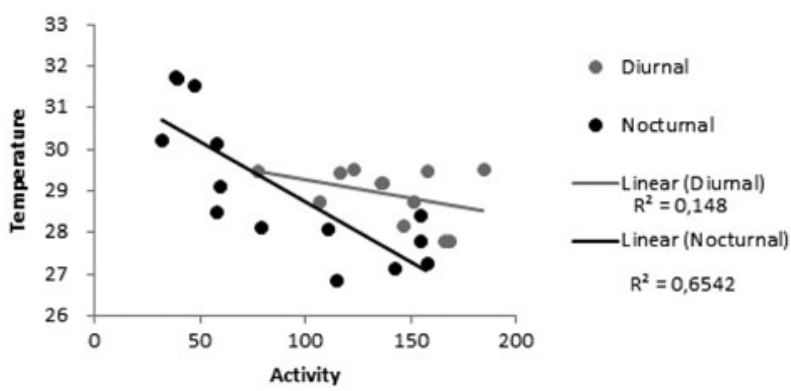

Figure 2. Correlations between nocturnal and diurnal activity and temperature by groups. 


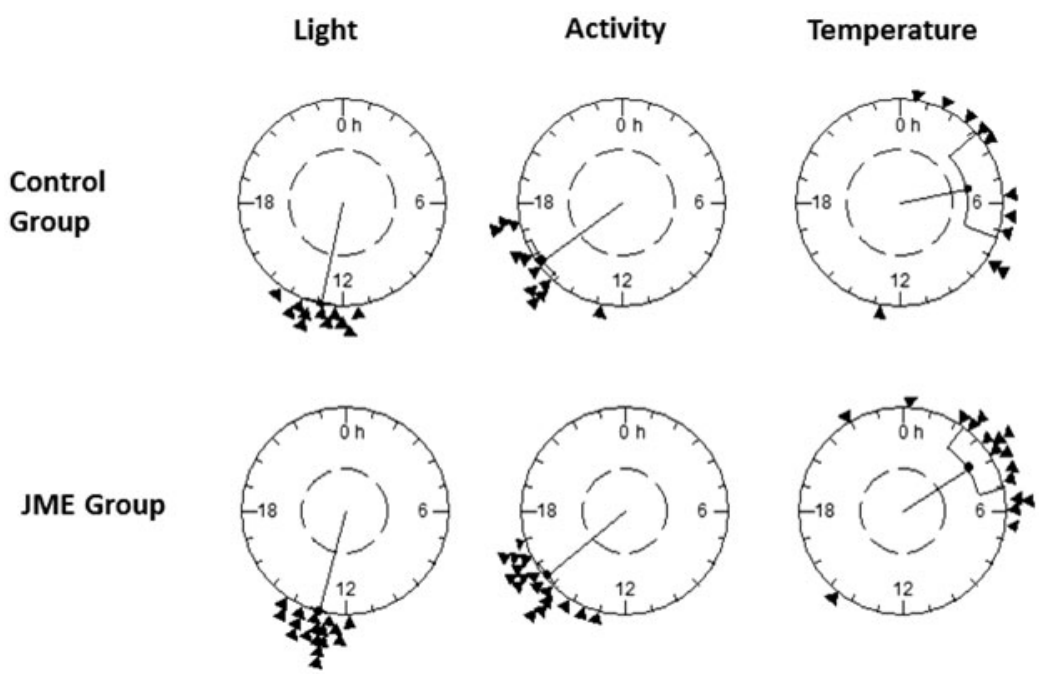

Figure 3. Rayleigh analysis by groups.

\section{Discussion}

In our study, patients with epilepsy exhibited lower average schooling levels, a finding likely related to the limitations imposed by the disease, its treatment or the stigma attached to the disorder.

The finding of greater correlation between activity-rest and temperature rhythms in the epilepsy patients, particularly at night, is noteworthy. We believe that this effect may be related to the use of valproic acid by JME patients. Greater association was observed between the rhythms despite the fact that psychiatric disorders were more common in the epilepsy patients than controls. The opposite was true in a study comparing healthy controls with depressed patients. In that study, the difference between day and night in correlations between temperature and activity rhythms was higher in the depressed group than among controls (Moraes et al. 2013).

Patients with JME may be predisposed to hypersynchrony between their biological rhythms. This hypothesis can be confirmed through future studies, but the correlation between lifestyle regularity scores and disease onset reinforce this hypothesis. Inverse correlation occurred despite disease duration of symptoms stabilization time. This probably indicates that early onset of the disease damages the temporal systems or may be related to overprotective behavior by caregivers, reinforcing the social zeitgeber.

In the social rhythm metric, patients exhibited similar regularity scores to controls, in contrast to what would be expected based on the literature (Punz \& Schmitz 2006; Ryasi et al. 2008). This may be due to treatment interference or differences between the characteristics of the samples studied.

Our study has certain limitations, namely the small sample of patients and our inability to control all the possible variables involved. In addition, it would be interesting to include a group of patients with JME who were not on medication. The result may also have been affected by depressive symptoms, despite the finding of a trend as opposed to a statistical difference. However, the present study also has important strengths, namely that it is the first investigation to assess circadian variables in epileptic 
patients, making it possible to analyze synchronization between these variables and its association with clinical presentation. Finally, the method used here is a chronobiological approach that may assist in developing new treatment strategies.

\section{Conclusion}

This study found a higher correlation between chronobiological variables in epileptic patients than controls, which may reflect the function of the body's internal clock. Experimental studies are needed to test the underlying circadian mechanism that regulates epileptic seizures and how it relates to disease chronicity.

\section{Disclosure}

This study was fully supported by Incentive Fund for Research and Events of Hospital de Clínicas de Porto Alegre - FIPE/HCPA, FAPERGS and CNPQ. The funders had no role in study design, data collection and analysis, decision to publish, or preparation of the manuscript. None of the authors has any conflict of interest to disclose. We confirm that we have read the Journal's position on issues involved in ethical publication and affirm that this report is consistent with those guidelines.

\section{References}

Almeida CAV, Lins OG, Lins SG, Laurentino S, Valença MM. 2003. Distúrbios do sono na epilepsia do lobo temporal [Sleep disorders in temporal lobe epilepsy]. Arq Neuropsiquiatr. 61 (4):979-987.

Bazil CW, Short D, Crispin D, Zheng W. 2000. Patients with intractable epilepsy have low melatonin, which increases following seizures. Neurology. 55(11):1746-1748.

Gorestein C, Andrade LHSG. 2000. Inventário de depressão de Beck: propriedades psicométricas da versão em português [Beck depression inventory: psychometric properties of Portuguese version]. In: Gorestein C, Andrade LHSG, Zuardi AW, orgs. Escalas de avaliação clínica em psiquiatria e psicofarmacologia [Scales of clinical evaluation in psychiatry and psychopharmacology]. São Paulo: Lemos; p. 89-95.

Herman ST, Walczak TS, Bazil CW. 2001. Distribution of partial seizures during the sleep-wake cycle: differences by seizure onset site. Neurology. 56(11):1453-1459.

Hofstra WA, deWeerd AW. 2009. The circadian rhythm and its interaction with human epilepsy: a review of literature. Sleep Med Rev. 136:412-420.

Hofstra WA, Grootemarsink BE, Dieker R, van der Palen J, de Weerd AW. 2009. Temporal distribution of clinical seizures over the 24-h day: a retrospective observational study in a tertiary epilepsy clinic. Epilepsia. 50(9):2019-2026.

Horne JA, Ostberg O. 1976. Self-assessment questionnaire to determine morningness-eveningness in human circadian rhythms. Int J Chronobiol. 4:97-110.

Laakso ML, Leinonen L, Hatonen T, Alila A, Heiskala H. 1993. Melatonin, cortisol and body temperature rhythms in Lennox-Gastaut patients with or without circadian rhythm sleep disorders. J Neurol. 240(7):410-416.

Moraes CA, Cambras T, Noguera AD, Schimitt RL, Dantas G, Levandovski R, Hidalgo MP. (2013). A new chronobiological approach to discriminate between acute and chronic depression using peripheral temperature, rest-activity and light-exposure parameters. BMC Psychiatry. 13:77-87.

Noguera AD. Available from: www.el-temps.com.

Parain D, Blondeau C. 2000. Photosensitive epilepsy and television epilepsy. Arch Pediatr. 7 (1):89-90.

Punz T, Schmitz B. 2006. Circadian rhythm and personality profile in juvenile myoclonic epilepsy. Epilepsia. 47(2):111-114. 
Robinson E, DiIorio C, DePadilla L, McCarty F, Yeager K, Henry T, Schomer D, Shafer P. 2008. Psychosocial predictors of lifestyle management in adults with epilepsy. Epilepsy Behav. 13 (3):523-528.

Rowland D, Arkkelin D, Crisler L. 1991. Computer-based data analysys: using SPSS in the social sciences. Chigago, IL: Wardsworth. Nelson-hall series in psychology.

Ryasi HR, Taheri MMH, Rezvani MR, Nakhaei F, Salehi F. 2008. Clinical evaluation of 32 patients with juvenile myoclonic epilepsy in southern khorasan. Iran. J. Neurol. 7 (23):290-296.

Schimitt RL, Hidalgo MP, Caumo W. 2010. Ritmo social e suas formas de mensuração: uma perspectiva histórica [Social rhythm and their measurement types: a historical overview]. Estudos e Pesquisas em Psicologia. 2:457-470.

Schimitt RL, Zanetti T, Mayer M, Koplin C, Guarienti F, Hidalgo MP. 2010. Psychometric properties of social rhythm metric in regular shift employees. Rev Bras Psiquiatr. 32(1):47-55.

Yang Z, Cai X, Liu X, Qin J. 2008. Relationship among eye condition sensitivities, photosensitivity and epileptic syndromes. Chin Med J. 121(17):1633-1637. 
Copyright of Biological Rhythm Research is the property of Taylor \& Francis Ltd and its content may not be copied or emailed to multiple sites or posted to a listserv without the copyright holder's express written permission. However, users may print, download, or email articles for individual use. 